\title{
Selenium, iodine, $\omega-3$ PUFA and natural antioxidant from Melissa officinalis L.: a combination of components from healthier dry fermented sausages formulation
}

Mikel García-Íñiguez de Ciriano ${ }^{1}$, Eduardo Larequi ${ }^{1}$, Sheyla Rehecho ${ }^{2}$, Maria Isabel Calvo $^{2}$, Rita Yolanda Cavero ${ }^{3}$, Íñigo Navarro-Blasco ${ }^{4}$, Iciar Astiasarán ${ }^{1}$, Diana Ansorena $^{1} *$

${ }^{1}$ Department of Nutrition, Food Science, Physiology and Toxicology, Faculty of Pharmacy, University of Navarra, Irunlarrea s/n, 31008-Pamplona, Spain.

2 Department of Pharmacy and Pharmaceutical Technology, Faculty of Pharmacy, University of Navarra, Irunlarrea s/n, 31008-Pamplona, Spain.

${ }^{3}$ Department of Plant Biology (Botany), Faculty of Sciences, University of Navarra, Irunlarrea s/n, 31008-Pamplona, Spain.

4 Department of Chemistry and Soil Science, Faculty of Sciences, University of Navarra. Irunlarrea s/n, 31008-Pamplona, Spain.

*Corresponding author: Tel.: +34 948425600 (ext. 6263); Fax: +34 948425649. E-mail address: dansorena@unav.es 


\section{ABSTRACT}

A new formulation of dry fermented sausage, including ingredients that contribute to improve the nutritional and health benefits of this type of products is presented. Se yeast $(2 \mathrm{~g} / \mathrm{kg})$, iodized salt (26 g/kg), linseed:algae (3:2) emulsion (62.5 $\mathrm{g} / \mathrm{kg}$ ), and lyophilized water extract of Melissa officinalis L. as source of natural antioxidants $(686 \mathrm{mg} / \mathrm{kg})$, allowed to obtain dry fermented sausages with technological and sensorial properties similar to traditional ones.

From the nutritional standpoint, a $50 \mathrm{~g}$ portion of this product would cover a 100 $\%$ of the recommended intake value for Se, a $70 \%$ of DRI for iodine, and a $40 \%$ and $100 \%$ of the labeling reference intake for $\alpha$-linolenic and EPA+DHA, respectively. The $\omega-6 / \omega-3$ ratio decreased from 15.7 in the control product to 1.96 in the modified one. Despite the high PUFA content, no oxidation signs were detected by TBARS $(<0.15 \mathrm{mg}$ $\mathrm{MDA} / \mathrm{kg}$ ) and volatile compounds, pointing at the effectiveness of the proposed natural antioxidant from Melissa officinalis.

The modified formulation presented good acceptability for panelists and similar appearance, odor, taste and juiciness with control products.

Keywords: functional foods; Se yeast; iodized salt; natural antioxidant; linseed and algae oils. 


\section{INTRODUCTION}

The lipid modification of meat products by means of a substitution of pork back fat by other lipid sources has been demonstrated to be a good strategy to improve their nutritional quality (Lee, Faustman, Djordjevic, Faraji, \& Decker, 2006; Pelser, Linssen, Legger, \& Houben, 2007; Jiménez-Colmenero, 2007; Martin, Ruiz, Kivikari \& Puolanne, 2008; Del Nobile, Conte, Incoronato, Panza, Sevi \& Marino, 2009). In this sense, fish and algae oils present a high nutritional interest due to their high content in long chain $\omega-3$ PUFA and are able to be included in dry fermented sausages formulation, at least at a 15\% substitution level (Valencia, Ansorena \& Astiasarán, 2006; Valencia, Ansorena \& Astiasarán, 2007). The linseed oil, which presents an important content of $\omega-3$ PUFA, basically $\alpha$-linolenic acid, has been used in dry fermented sausages in a substitution of $25 \%$ of the pork back fat, reporting very interesting results in the sensorial properties and in the stability of the product (Ansorena \& Astiasarán, 2004a; García-Íñiguez de Ciriano, García-Herreros, Larequi, Valencia, Ansorena \& Astiasarán, 2009). However, to our knowledge, no works have been performed in which a combination of different oils is assayed in order to profit the health benefits of each one of the elements of the mixture.

Previous papers have also evidenced the need of including antioxidants in highly unsaturated fat containing meat products, as this type of fatty acids are associated to a higher oxidation susceptibility. Although artificial antioxidants have been traditionally used (Ansorena \& Astiasarán, 2004b), novel approaches using natural antioxidants are currently very well appreciated (Hernández-Hernández, Ponce-Alquicira, JaramilloFlores \& Guerrero Legarreta, 2009; García-Íñiguez de Ciriano, García-Herreros, Larequi, Valencia, Ansorena \& Astiasarán, 2009; Haak, Raes \& De Smet, 2009). These 
antioxidants could have a beneficial health effect at a biological level, beyond performing their technological role by controlling the oxidation process in the product.

In this sense, a cause and effect relationship has also been established between the dietary intake of selenium and protection of DNA, proteins, lipoproteins and lipids from oxidative damage as it is a component of selenoproteins, some of which have important antioxidant properties (Rayman, 2000). Recommended Se intakes for humans (55 $\mu \mathrm{g} /$ day) are not currently achieved in the majority of European countries, and furthermore, this recommended intake levels do not take into account the fact that higher levels of Se intake appear to confer additional health benefits besides its implication on the activity of selenoenzymes (Rayman, 2004). In order to achieve these positive effects, a number of intervention studies have been performed using selenium enriched yeast as the intervention agent at different doses, between 100-600 $\mu \mathrm{g} /$ day, (Aaseth, Haugen \& Forre, 1998; Marshall, 2001; Larsen, Hansen, Paulin, Moesgaard, Reid \& Rayman, 2004), some of them far above the presumible tolerable upper intake level established nowadays at $300 \mu \mathrm{g} /$ day.

On the other hand, iodine deficiency remains a major public health problem in Europe and in some other world areas (WHO, 2007), causing goitre as its main clinical manifestation, and brain damage and irreversible mental retardation as other consequences. Salt iodization is proposed as the main strategy to control this deficiency. As an increasingly smaller amount of salt is consumed as table salt and a clear trend towards a greater proportion of salt in processed foods is detected, the food industry seems to play an important role in the contribution to eradicate iodine deficiency. However, the use of iodine as an ingredient in processed foods has received still little research attention and there are insufficient data available to describe which foods will be suitable and inert vehicles for iodine fortification (Winger, König \& House, 2008). 
The objective of this work was to evaluate the feasibility of using a combination of sources of interesting functional compounds ( $\omega-3$, Selenium, iodine and natural antioxidants) within a new formulation of dry fermented sausage, making it optimum from the technological, sensorial and nutritional point of view. 


\section{MATERIALS AND METHODS}

\section{Lyophilized water extracts of Melissa officinalis}

\section{Preparation of extract}

Water extracts of Melissa officinalis were prepared as follows: $50 \mathrm{~g}$ of dried leaves were weighted and added to $500 \mathrm{ml}$ of distilled water, preheated at $100{ }^{\circ} \mathrm{C}$. The mixture was subjected to reflux during 30 minutes at the temperature above. Extraction process was repeated with another $500 \mathrm{ml}$ of distilled water, and both extracts were joined and completed with distilled water to a final volume of $1 \mathrm{~L}$. Extracts were filtered using filter to remove insoluble particles. Water extraction was performed in triplicate.

The extracts were lyophilized with a freeze-dryer-cryodo (Telstar, Barcelona, Spain), previous freezing at $-80^{\circ} \mathrm{C}$ in a MDF-V5386S Ultra-Low-Temperature Freezer (Sanyo Electric Co., Ltd., Japan). 21.8 g of lyophilized material were obtained from 100 $\mathrm{g}$ of Melissa dried leaves. The lyophilized material was subsequently used for the evaluation of the antioxidant capacity and for application as ingredient in the dry fermented sausage formulation.

\section{Characterization of antioxidant capacity}

Determination of Total phenolic content (TPC)

TPC was determined spectrophotometrically following the Folin-Ciocalteu colorimetric method (Singleton \& Rossi, 1965) with some modifications (GarcíaHerreros, García-Íñiguez de Ciriano, Ansorena \& Astiasarán, in press). The total phenolic content was expressed as $\mathrm{mg}$ equivalents of Gallic acid (mg GAE)/g lyophilized extract. Absorbance measurements were made in duplicate for each diluted 
solution. Dilutions of lyophilized extract between 0.2 and $0.001 \mathrm{mg} / \mathrm{ml}$ were prepared for further analysis.

DPPH method

The DPPH assay was performed according to the method of Blois (1958) with modifications described by García-Herreros, García-Íñiguez de Ciriano, Ansorena and Astiasarán (In press). Results were finally expressed as mg Trolox/g lyophilized extract of Melissa officinalis. Absorbance measurements were done in duplicate for each dilution of lyophilized extract.

ABTS method

For ABTS assay, the procedure described by Re, Pellegrini, Proteggente, Pannala, Yang and Rice-Evans (1999) with some modifications described by GarcíaHerreros, García-Íñiguez de Ciriano, Ansorena and Astiasarán (In press), was used. Results were finally expressed as $\mathrm{mg}$ Trolox/g lyophilized extract of Melissa. Absorbance measurements were made in duplicate for each diluted solution.

\section{Sausage formulation and processing}

Two batches of dry fermented sausages (chorizo de Pamplona), about $8 \mathrm{~kg}$ each, were prepared according to the procedure described by Muguerza, Gimeno, Ansorena, Bloukas and Astiasarán (2001). The control batch was elaborated using 75\% lean pork meat and $25 \%$ pork back fat. In the modified batch, a substitution of $25 \%$ of pork back fat by an emulsion containing a mixture of linseed oil (Biolasi. Productos Naturales, Guipúzcoa, Spain) and algae oil (DHASCO ${ }^{\circledR}$ oil, a commercially available oil obtained from Crypthecodinium cohnii, Martek Biosciences Corporation, Columbia., USA) was carried out. The mixture was linseed oil: algae oil (3:2), and the resulting fatty acid 
profile ( $\mathrm{g} / 100 \mathrm{~g}$ of fatty acids) is shown in Table 1 . The emulsion was prepared mixing, for two minutes, eight parts of hot water with one part of isolated soy protein and then with ten parts of the oils mixture for other three minutes.

In the control batch $26 \mathrm{~g} / \mathrm{kg}$ of common salt $(\mathrm{NaCl})$ were added and in the modified $26 \mathrm{~g} / \mathrm{kg}$ of iodized salt were used $(60 \mu \mathrm{g}$ Iodine $/ \mathrm{g}$ salt). In addition, in the modified batch $2 \mathrm{~g} / \mathrm{kg}$ of Selenium yeast were included (Guinama. Valencia, Spain) and $686 \mathrm{ppm}$ of lyophilized water extract of Melissa officinalis L. were used as a source of natural antioxidants. The following ingredients per kilogram of meat mixture were added to both formulations: red pepper $30 \mathrm{~g}$, dextrin $15 \mathrm{~g}$, lactose $10 \mathrm{~g}$, powdered milk $12 \mathrm{~g}$, dextrose $5 \mathrm{~g}$, sodium ascorbate $0.5 \mathrm{~g}$, sodium caseinate $10 \mathrm{~g}$, garlic $3 \mathrm{~g}$, polyphosphates $2 \mathrm{~g}$, curing agents (a mixture of $\mathrm{NaCl}$, preservatives $\mathrm{E}-250$, E-252 and antioxidant E-331) 3 g, ponceau 4R (E-124) 0.15 g. Sausages were fermented and ripened for 30 days under conditions described by Muguerza, Gimeno, Ansorena, Bloukas, and Astiasarán (2001) in a drying chamber (STA model W 80XDHG-VEH Noain, Spain). The analysis was carried out at the end of the ripening process.

\section{Chemical analysis.}

The method of Folch, Lees and Stanley (1957) was used for the extraction of lipids. Fatty acids were determined in the lipid extract by gas chromatography according to the procedure described by Valencia, O’Grady, Ansorena, Astiasarán and Kerry (2008).

TBARS value was determined according to Tarladgis, Watts, Younathan, and Dugan (1960) with modifications by Tarladgis, Pearson and Dugan (1964). Results are shown in mg malonaldehyde (MDA)/kg sample (ppm). 


\section{Volatile compounds from lipid oxidation}

A Likens-Nickerson extraction using dichloromethane was carried out according to the method described by Ansorena, Zapelena, Astiasarán and Bello (1998). $25 \mathrm{~g}$ of frozen sausage were ground and placed in a $250 \mathrm{ml}$ flask with $100 \mathrm{ml}$ of water. A second flask with $5 \mathrm{ml}$ of dichloromethane and $150 \mu \mathrm{g}$ of dodecane (internal standard) was also attached to a modified Likens-Nickerson apparatus. $5 \mathrm{ml}$ of dichloromethane were also added to fill the apparatus solvent return loop. Both solvent and sample mixture were heated to $70^{\circ} \mathrm{C}$ and boiling temperature, respectively, maintaining these conditions for $2 \mathrm{~h}$. After cooling to ambient temperature, the extract of dichloromethane was collected and dried over anhydrous $\mathrm{Na}_{2} \mathrm{SO}_{4}$.

Analysis. Some volatile compounds (hexanal, decadienals and nonadienals) were analyzed in a HP 6890 GC system (Hewlett-Packard, Palo Alto, USA) coupled to a 5973 mass selective detector (Hewlett-Packard). A total of $1 \mu l$ of the extract was injected into the GC, equipped with a capillary column $(30 \mathrm{~m} \mathrm{X} 250 \mu \mathrm{m}$ X $0.25 \mu \mathrm{m}$ nominal HP-5MS). The chromatographic conditions were described by Ansorena and Astiasaran (2004b).

\section{Analytical procedure for selenium determination}

$0.5 \mathrm{~g}$ of homogenized dried fermented sausages were accurately weighed, placed in a high pressure teflon digestion vessel and treated with $7 \mathrm{ml}$ of sub-boiling nitric acid and $2 \mathrm{ml}$ of tracepur hydrogen peroxide (Merck) in a microwave digestion system (Ethos Plus, Millestone s.r.l., Sorisole, Italy). The optimised microwave digestion programme applied included two steps: $25-170{ }^{\circ} \mathrm{C}$ for $10 \mathrm{~min}$. and $170{ }^{\circ} \mathrm{C}$ for $10 \mathrm{~min}$ both at $1000 \mathrm{~W}$, immediately followed by ventilation at room temperature. Digested 
samples in triplicate were diluted to $10 \mathrm{ml}$ in a volumetric flask with ultrapure water and finally, transferred to pre-cleaned polypropylene tubes.

Selenium concentrations were determined in sample digestions by Zeeman background correction graphite furnace atomic absorption spectrometry (ZGF-AAS, Perkin Elmer AAnalyst 800, Norwalk, CT, USA) at $196.0 \mathrm{~nm}$ with a spectral band width of $2.0 \mathrm{~nm}$. Transversely-heated graphite tubes with end caps supplied by Perkin Elmer were used. An electrodeless discharge lamp (Perkin Elmer) was operated at 280 $\mathrm{mA}$. Injections of $20 \mu \mathrm{l}$ sample and $15 \mu \mathrm{l}$ matrix modifier were made in triplicate.

Detection limit (LOD) was set at three times the standard deviation of the reagent blank, was expressed in terms of wet weight sausage, corresponding to $0.08 \mu \mathrm{g}$ $100 \mathrm{~g}^{-1}(\mathrm{n}=6)$. Analytical recoveries $(99.4 \pm 1.3 \%)$ were determined from the SRM 1577b (NIST Bovine liver) in order to test the accuracy of the method. The found value $\left(0.73 \pm 0.03 \mathrm{mg} \mathrm{Kg}^{-1}, \mathrm{n}=6\right)$ show acceptable good agreement with SRM selenium certified value $\left(0.73 \pm 0.06 \mathrm{mg} \mathrm{Kg}^{-1}\right)$.

Details of measurements and analytical procedures are discussed elsewhere (Navarro \& Barbarin, 2009; Sola \& Navarro, 2009).

\section{Sensory evaluation}

A triangular test was performed to determine the existence of perceptible sensorial differences in appearance, odor and taste between the two batches. 16 trained panelists participated in the sessions. Samples were presented sliced, on a white plate, at room temperature. Each panelist was presented with three samples, of which two were identical, and asked to indicate which sample differed from the others. The number of correct answers was determined and data shown in the table corresponded to the mean value obtained for each type of product by 16 members taking into account data given 
by all panelists. According to the Norma UNE 87-006-92 (1992), the difference between samples was significant if the number of correct answers was $9(p<0.05), 11$ $(\mathrm{p}<0.01)$ and $12 \quad(\mathrm{p}<0.001)$. Panelists were also asked to evaluate the general acceptability of the samples in a continuous scale between 0 and 10 . A value of 0 corresponded to the lowest score for acceptability and a value of 10 to the highest.

\section{Data Analysis.}

Four samples were analyzed from each type of dry fermented sausage. Each parameter was determined four times in each sample. In tables, means and standard deviations are shown.

Student $t$ test was used to determine significant differences $(p<0.05, p<0.01$, $\mathrm{p}<0.001)$ between the two types of sausages. The statistics package chosen for analysis was SPSS version 15.0 (SPSS inc. Chicago, Illinois, USA). 


\section{RESULTS AND DISCUSSION}

\section{Nutritional evaluation}

General composition data of control and modified sausages did not reveal significant differences $(\mathrm{p}<0.05)$ in fat content $(31.9 \mathrm{~g} / 100 \mathrm{~g}$ for control and $32.9 \mathrm{~g} / 100 \mathrm{~g}$ for modified product) and protein content $(23.8 \mathrm{~g} / 100 \mathrm{~g}$ for control and $25.8 \mathrm{~g} / 100 \mathrm{~g}$ for modified sausage), leading also to a similar total energy value (403 kcal/100 $\mathrm{g}$ for control and $421 \mathrm{kcal} / 100 \mathrm{~g}$ for modified). Thus, macronutrient distribution was similar for both products.

Table 1 presents the fatty acid profile of the two types of sausages $(\mathrm{g} / 100 \mathrm{~g}$ of fatty acids). As expected, the main changes in the modified products compared to the traditional formulation affected those fatty acids which characterizes the two types of oils used in the emulsion included in this new sausage. $\alpha$-linolenic acid, highly present in linseed oil, was $4.8 \mathrm{~g} / 100 \mathrm{~g}$ of fatty acids, about 5-fold the value found in control sausage, and docosahexaenoic acid, typically present in Cripthecodinium conhii algae oil, was $2 \mathrm{~g} / 100 \mathrm{~g}$ of fatty acids, about 4-fold the value found for control products. Consequently, the supply of PUFA increased from $5.35 \mathrm{~g} / 100 \mathrm{~g}$ product to $6.70 \mathrm{~g} / 100 \mathrm{~g}$ product, which implied a relevant modification in the $\omega 6 / \omega 3$ ratio. This ratio was 15.7 for control products, whereas it significantly decreased to 1.95 in the sausages with the mixture of linseed and algae oils. Valencia, Ansorena and Astiasarán (2007), using a 15 $\%$ substitution of pork backfat by algae oil (Schizochytrium sp.) in the same type of dry fermented sausages achieved a $\omega-6 / \omega-3$ ratio of 2.6 , whereas a ratio of 2.1 was detected with a $25 \%$ substitution of pork backfat by linseed oil (Ansorena \& Astiasarán, 2004a).

According to the Scientific Opinion of the Panel on Dietetic Products, Nutrition and Allergies, the proposed labeling reference intake value for $\alpha$-linolenic acid is $2 \mathrm{~g}$ for 
a $1800 \mathrm{kcal} /$ day diet, and the value for EPA+DHA is $250 \mathrm{mg}$ /day (EFSA, 2009a). Considering that one portion of dry fermented sausage is $50 \mathrm{~g}$, this amount would supply $0.8 \mathrm{~g} \alpha$-linolenic acid and $338 \mathrm{mg}$ EPA + DHA, covering a $40 \%$ and more than a $100 \%$ of the labeling reference intakes proposed by the EFSA for these fatty acids, respectively, which are intended to represent typical recommended daily intakes for adults (EFSA, 2009a).

Besides the intervention on the lipid fraction, changes in the mineral content of the new products were performed, aiming to improve their nutritional and health benefits. Vignola et al. (2009) enriched meat with Se yeast, concluding that this strategy provided an interesting form of dietary Se that could be used to improve human Se status. They reported a concentration of total Se in $L$. dorsi of lambs of $0.66-0.84 \mu \mathrm{g} / \mathrm{g}$ dry weight after the dietary administration of different levels of Se yeast. Thus, a $125 \mathrm{~g}$ portion of this meat would provide approximately $25 \mu \mathrm{g}$ Se. Total Se found in the new formulation products developed in this work was $364 \mu \mathrm{g}$ Se/100g sausage, coming mainly from the Se yeast added in the formulation, whereas control sausages contained only $1.2 \mu \mathrm{g} / 100 \mathrm{~g}$ sausage. Se from yeast is typically organic, basically in the form of seleno-aminoacid selenomethionine $(60-85 \%$ of total Se), and the content of other organic selenium compounds including Se-Cys does not exceed 10\%, being inorganic residue lower than $1 \%$. Se yeast is capable of increasing the activity of selenoenzymes and its bioavailability has been shown to be approx 1.5 to 2 fold higher than that of inorganic form of selenium (EFSA, 2009b). These results pointed out that the incorporation of Se yeast into this new meat product permitted achieving a final concentration of an excellent bioavailable Se source, equivalent to those used in human intervention studies in which different beneficial health effects have been demonstrated. 
Following the WHO indication of a universal salt iodization, modified dry fermented sausages were elaborated with iodized salt. Other strategies in the meat products sector have tried wheat fibre and soy isolate impregnated with iodine salts to fortify processed meats to improve the nutritional quality of this type of products (Waszkowiak \& Szymandera-Buszka, 2008). Also Kuhne, Wirth and Wagner (1993) assayed iodized nitrite curing salt as a iodine source in the elaboration of frankfurters, cooked and cured products. Food law regulations establish the iodine concentration for iodized salt, for instance in Spain it is established in $60 \mathrm{ppm}$ of iodine (BOE, 1983). This means that the new formulation supplies approximately $208 \mu \mathrm{g}$ iodine/100 $\mathrm{g}$ product, making it a "high iodine" product (EU Regulation 1924/2006). Current international recommended intakes for iodine are established in $150 \mu \mathrm{g} / \mathrm{day}$ for adults and in $220 \mu \mathrm{g} /$ day for pregnant and lactating women. A $50 \mathrm{~g}$ portion of this product would contain approximately a $70 \%$ of the RDI in adults and a $47 \%$ of it in pregnant and lactating woman.

The interest in public health of the enrichment of iodine in foods has given rise in the last years to evaluate the stability of the different iodized salts during processing and storage of iodine enriched foods, although the difficulty in the analysis of iodine in a food system limit the number of this type of works. Waszkowiak and SzymanderaBuszka (2008) analyzing the changes in iodine content in fortified pork dishes found retention percentages between $69-100 \%$ during cold storage (1-3 days) and $31-100 \%$ during frozen storage (1-150 days) when iodized table salt was used as carrier. Considering these data, could be expected a reasonable stability for iodine in this type of products, which are not subjected to drastic conditions during their processing and storage, although further analyses of iodine should be made to confirm its final amount. 


\section{Evaluation of oxidation}

In order to control the potential oxidation of the new formulation, rich in PUFA, a lyophilized water extract of Melissa officinalis was used as a natural antioxidant source. The evaluation of the antioxidant activity of this extract showed values of $307.06 \mathrm{mg}$ Trolox/g of lyophilized extract using the DPPH method and $437.38 \mathrm{mg}$ Trolox/g of lyophilized extract for ABTS test. Total Phenolic Compounds were 162.63 mg of GAE/g of lyophilized extract being the rosmarinic acid the most abundant one (data not shown).

The control of the oxidation process was carried out monitoring the TBARS during the ripening process (figure 1), being all values very low (below $0.15 \mathrm{mg}$ MDA/kg) and without noticing significant differences between products. A slight decrease was observed at the $10^{\text {th }}$ day of curing, probably attributed to the combination of aldehydes with other compounds and the loss of volatile aldehydes (Severini, De Pilli \& Baiano, 2003). Furthermore, the analysis of the profile of volatile compounds derived from oxidation in the final modified product was also performed. Aldehydes are mainly those volatile compounds resulting from lipid oxidation (Ansorena, Zapelena, Astiasarán \& Bello, 1998), with hexanal as a typical oxidation marker coming from linoleic acid degradation (Sahidi \& Pegg, 1994). This compound showed a value of 624 ng dodecane/g dry mater, comparable to those values found for dry fermented sausages elaborated with $15 \%$ algae oil and BHT (Valencia, Ansorena \& Astiasarán, 2007) or to products with 25\% linseed oil and natural antioxidants (García-Íñiguez de Ciriano, García-Herreros, Larequi, Valencia, Ansorena \& Astiasarán, 2009). Furthermore, these values are within the same order of magnitude than those observed for commercial dry fermented sausages (Ansorena, Gimeno, Astiasarán \& Bello, 2001) and for linseed oil containing sausages and BHT (Ansorena \& Astiasarán, 2004a). No decadienals or 
nonadienal were detected in the new formulation. All these results confirmed the efficacy of the lyophilized water extract of Melissa as a natural antioxidant agent, controlling the development of oxidation signs.

\section{Sensory quality}

The potential health benefits of the developed sausages could only be effective if the product show a good acceptability for the consumers from the sensory standpoint. Results of TPA analysis did not show significant differences between both products $(\mathrm{p}<0.05)$, finding the following values for the modified formulation: $3299 \pm 729 \mathrm{~g}$ for hardness, $0.63 \pm 0.06 \mathrm{~mm}$ for springiness, $0.54 \pm 0.03$ for cohesiveness, $1776 \pm 426 \mathrm{~g}$ for gumminess and $878 \pm 114 \mathrm{~g} \mathrm{x} \mathrm{mm}$ for chewiness. These values are similar to those obtained by Gimeno, Astiasarán and Bello (2001) in a traditional dry fermented sausage. The inclusion of the emulsion at a $25 \%$ level of substitution of pork backfat did not affect the rheological properties of the new product, despite the difference in consistency between the two mainly lipidic raw matters used in the formulations.

In relation to the instrumental evaluation of color, results are shown in table 2. Lightness $\left(\mathrm{L}^{*}\right)$ was the only parameter not significantly affected by the new formulation $(p>0.05)$. Some differences were found for chromaticity parameters $\left(a^{*}\right.$ and $\left.b^{*}\right)$, that led to instrumental differences in the saturation parameter or chroma, and in the hue angle. Nevertheless, both hue and chroma values kept within the normal range for this type of products (Gimeno, Ansorena, Astiasarán \& Bello, 2000) and, as it will be discussed later, no influence was exerted on the final appearance evaluation made by the sensory panel. In fact, previous works on meat products colour have evidenced that sensory and instrumental results were comparable for redness but panellists were unable to detect the measured differences in yellowness (Sandusky, 1994). 
Although differences between the control product and the developed product would not always mean that the new one were worse, a sensory triangular test was carried out as a simple evaluation of possible differences on appearance, odor, taste and juiciness between control and modified products (table 3). Results revealed that consumers were not able to distinguish samples on basis on these parameters $(p>0.05)$. In a $62.5 \%$ of the cases, the panelists indicated that both types of samples were identical for appearance, taste and juiciness, whereas in a $56.3 \%$ of cases, odour was considered similar for both samples. In general, it could be concluded that only in the 40 $\%$ of cases approximately correct replies were reported when panelists were asked to detect differences between products, despite the introduced changes in the formulation. Furthermore, when panelists were asked about the general acceptability of samples, mean score received by modified products (7.38) was similar to that obtained for control ones $(8.14)(p<0.05)$ on a continuous $0-10$ scale. Thus, the incorporation of the new ingredients did not influence the sensorial quality of the products. Wirth and Kuhne (1991) evaluated the use of iodized salt in a wide range of processed meat products, concluding that there were no changes in sensory properties or curing characteristics of products. No other information about the influence of the rest of new compounds used in the new formulation on sensorial quality of foods has been found.

In summary, the developed formulation gave rise to a dry fermented sausage formulation with $0.8 \mathrm{~g} \alpha$-linolenic acid, $338 \mathrm{mg}$ EPA+DHA, $182 \mu \mathrm{g}$ Se and an expected amount of $104 \mu \mathrm{g}$ iodine per portion (50 g) with a good sensory quality and stabilized by natural antioxidant from lyophilized water extracts of Melissa officinalis. 


\section{ACKNOWLEDGEMENTS}

We thank the "Programa Consolider-Ingenio 2010 CARNISENUSA CSD200700016" and the "Proyecto AGL2008-01099/ALI" (Ministerio de Ciencia e Innovación), and the "Plan Investigador de la Universidad de Navarra" (PIUNA) for their contribution to the financial support of this work. We are also grateful to Dr. Mohino (ANVISA). 


\section{REFERENCES}

Aaseth, J., Haugen, M., \& Forre, O. (1998). Rheumatoid arthritis and metal compounds - perspectives on the role of oxygen radical detoxification. The Analyst, 123(1), 36.

Ansorena, D., Zapelena, M. J., Astiasarán, I., \& Bello, J. (1998). Addition of Palatase M (lipase from Rhizomucor miehei) to dry fermented sausages: Effect over lipolysis and study of the further oxidation process by GC-MS. Journal of Agricultural and Food Chemistry, 46(8), 3244-3248.

Ansorena, D., Gimeno, O., Astiasarán, I., \& Bello, J. (2001). Analysis of volatile compounds by GC-MS of a dry fermented sausage: chorizo de Pamplona. Food Research International, 34(1), 67-75.

Ansorena, D. \& Astiasarán, I. (2004a). The use of linseed oil improves nutritional quality of the lipid fraction of dry-fermented sausages. Food Chemistry, 87(1), 6974.

Ansorena, D. \& Astiasarán, I. (2004b). Effect of storage and packaging on fatty acid composition and oxidation in dry fermented sausages made with added olive oil and antioxidants. Meat Science, 67(2), 237-244.

Blois, M. S. (1958). Antioxidant determinations by the use of a stable free radical. Nature, 181(4617), 1199-1200. 
BOE. (1983). REAL DECRETO 1424/1983. Por el que se aprueba la Reglamentación Técnico-Sanitaria para la obtención, circulación y venta de sal y salmueras comestibles. BOE, 130, 15261-15264.

Del Nobile, M. A., Conte, A., Incoronato, A. L., Panza, O., Sevi, A., \& Marino, R. (2009). New strategies for reducing the pork back-fat content in typical Italian salami. Meat Science, 81(1), 263-269.

EFSA. (2009a).Scientific Opinion of the Panel on Dietetic Products, Nutrition and Allergies. Labelling reference intake values for n-3 and n-6 polyunsaturated fatty acids.Question n ${ }^{\circ}$ EFSA-Q-2009-00548EFSA J.1176,1-11

EFSA. (2009b).Scientific Statement of the Panel on Food Additives and Nutrient Sources added to Food (ANS). Inability to assess the safety of selenium amino acid chelate added for nutritional purposes as a source of selenium in food supplements and the bioavailability of selenium from this source based on the supporting dossier.Question n ${ }^{\circ}$ EFSA-Q-2006-223EFSA J.952,1-4

Folch, J., Lees, M., \& Stanley, G. H. S. (1957). A simple method for the isolation and purification of total lipides from animal tissues. The Journal of Biological Chemistry, 226(1), 497-509.

García-Herreros, C., García-Iñiguez de Ciriano, M., Astiasarán, I., \& Ansorena, D. (In press). Antioxidant activity and phenolic content of water extracts of Borago officinalis L.: influence of plant part and cooking procedures. Italian Journal of Food Science, 
García-Iñiguez de Ciriano, M., García-Herreros, C., Larequi, E., Valencia, I., Ansorena, D., \& Astiasarán, I. (2009). Use of natural antioxidants from lyophilized water extracts of Borago officinalis in dry fermented sausages enriched in $\omega-3$ PUFA. Meat Science, 83(2), 271-277.

Gimeno, O., Ansorena, D., Astiasarán, I., \& Bello, J. (2000). Characterization of chorizo de Pamplona: instrumental measurements of colour and texture. Food Chemistry, 69(2), 195-200.

Gimeno, O., Astiasarán, I., \& Bello, J. (2001). Calcium ascorbate as a potential partial substitute for $\mathrm{NaCl}$ in dry fermented sausages: effect on colour, texture and hygienic quality at different concentrations. Meat Science, 57(1), 23-29.

Haak, L., Raes, K., \& De Smet, S. (2009). Effect of plant phenolics, tocopherol and ascorbic acid on oxidative stability of pork patties. Journal of the Science of Food and Agriculture, 89(8), 1360-1365.

Hernández-Hernández, E., Ponce-Alquicira, E., Jaramillo-Flores, M. E., \& Guerrero Legarreta, I. (2009). Antioxidant effect rosemary (Rosmarinus officinalis L.) and oregano (Origanum vulgare L.) extracts on TBARS and colour of model raw pork batters. Meat Science, 81(2), 410-417.

Jiménez-Colmenero, F. (2007). Healthier lipid formulation approaches in meat-based functional foods. Technological options for replacement of meat fats by non-meat fats. Trends in Food Science \& Technology, 18(11), 567-578.

Kuhne, D., Wirth, F., \& Wagner, H. (1993). Iodine determination in iodized meatproducts. Fleischwirtschaft, 73(2), 175-178. 
Larsen, E. H., Hansen, M., Paulin, H., Moesgaard, S., Reid, M., \& Rayman, M. P. (2004). Speciation and bioavailability of selenium in yeast-based intervention agents used in cancer chemoprevention studies. Journal of AOAC International, 87(1), 225-232.

Lee, S., Faustman, C., Djordjevic, D., Faraji, H., \& Decker, E. A. (2006). Effect of antioxidants on stabilization of meat products fortified with $n-3$ fatty acids. Meat Science, 72(1), 18-24.

Marshall, J. R. (2001). Larry Clark's legacy: Randomized controlled, selenium-based prostate cancer chemoprevention trials. Nutrition and Cancer, 40(1), 74-77.

Martin, D., Ruiz, J., Kivikari, R., \& Puolanne, E. (2008). Partial replacement of pork fat by conjugated linoleic acid and/or olive oil in liver pâtés: Effect on physicochemical characteristics and oxidative stability. Meat Science, 80(2), 496504.

Muguerza, E., Gimeno, O., Ansorena, D., Bloukas, J. G., \& Astiasarán, I. (2001). Effect of replacing pork backfat with pre-emulsified olive oil on lipid fraction and sensory quality of Chorizo de Pamplona - a traditional Spanish fermented sausage. Meat Science, 59(3), 251-258.

Navarro-Blasco, I., \& Barbarin-Aizpún, C. (2009). Mineral and trace elements in meat products. In L. Nollet, \& F. Toldrá, Handbook of Processed Meats and Poultry Analysis(pp. 327-351). Boca Raton: CRC Press. 
Pelser, W. M., Linssen, J. P. H., Legger, A., \& Houben, J. H. (2007). Lipid oxidation in n - 3 fatty acid enriched Dutch style fermented sausages. Meat Science, 75(1), 111.

Rayman, M. P. (2000). The importance of selenium to human health. The Lancet, 356(9225), 233-241.

Rayman, M. P. (2004). The use of high-selenium yeast to raise selenium status: how does it measure up? The British Journal of Nutrition, 92(4), 557-573.

Re, R., Pellegrini, N., Proteggente, A., Pannala, A., Yang, M., \& Rice-Evans, C. (1999). Antioxidant activity applying an improved ABTS radical cation decolorization assay. Free Radical Biology Medicine, 26(9-10), 1231-1237.

Sandusky, C.L. (1994). Dissertation Abstract International, B55(4), p. 1243 Maryland.

Severini, C., De Pili, T., \& Baiano, A. (2003). Partial substitution of pork backfat with extra-virgin olive oil in 'salami' products: effects on chemical, physical and sensorial quality. Meat Science, 64 (3), 323-331.

Shahidi, F. \& Pegg, R. B. (1994). Hexanal as an indicator of the flavor deterioration of meat and meat products. ACS Symposium Series, (558), 256-279.

Singleton, V. L. \& Rossi, J. A. (1965). Colorimetry of total phenolics with phosphomolybdic-phosphotungstic acid reagents. American Journal of Enology and Viticulture, 16, 144-158. 
Sola-Larrañaga, C. \& Navarro-Blasco, I. (2009). Chemometric analysis of minerals and trace elements in raw cow milk from the community of Navarra, Spain. Food Chemistry, 112(1), 189-196.

Tarladgis, B. G., Watts, B. M., Younathan, M. T., \& Dugan, L. R., Jr. (1960). A distillation method for the quantitative determination of malonaldehyde in rancid foods. Journal of the American Oil Chemists' Society, 37(1), 44-48.

Tarladgis, B. G., Pearson, A. M., \& Dugan, L. R., Jr. (1964). Chemistry of 2thiobarbituric acid test for determination of oxidative rancidity in foods II. Formation of TBA-malonaldehyde complex without acid-heat treatment. Journal of the Science of Food and Agriculture, 15(9), 602-607.

UE REGULATION (CE). (2006). Num 1924/2006 of the European Parliament and of the Council of 20 December 2006 on nutrition and health claims made on foods. Official Journal of the European Union, L(404), 9-25.

UNE 87-006-92. (1992). Norma Española. Metodología Prueba Triangular.

Valencia, I., Ansorena, D., \& Astiasarán, I. (2006). Nutritional and sensory properties of dry fermented sausages enriched with n - 3 PUFAs. Meat Science, 72(4), 727-733.

Valencia, I., Ansorena, D., \& Astiasarán, I. (2007). Development of dry fermented sausages rich in docosahexaenoic acid with oil from the microalgae Schizochytrium sp.: Influence on nutritional properties, sensorial quality and oxidation stability. Food Chemistry, 104(3), 1087-1096.

Valencia, I., O’Grady, M. N., Ansorena, D., Astiasarán, I., \& Kerry, J. P. (2008). Enhancement of the nutritional status and quality of fresh pork sausages following 
the addition of linseed oil, fish oil and natural antioxidants. Meat Science, 80(4), 1046-1054.

Vignola, G., Lambertini, L., Mazzone, G., Giammarco, M., Tassinari, M., Martelli, G., \& Bertin, G. (2009). Effects of selenium source and level of supplementation on the performance and meat quality of lambs. Meat Science, 81(4), 678-685.

Waszkowiak, K. \& Szymandera-Buszka, K. (2008). The application of wheat fibre and soy isolate impregnated with iodine salts to fortify processed meats. Meat Science, 80(4), 1340-1344.

WHO. (2007). Iodine deficiency in europe A continuing public health problem. In (pp. 1-86) Geneva.

Winger, R. J., König, J., \& House, D. A. (2008). Technological issues associated with iodine fortification of foods. Trends in Food Science \& Technology, 19(2), 94-101.

Wirth, F. \& Kuhne, D. (1991). Manufactured of iodized meat-products. Fleischwirtschaft, 71(12), 1377-\&. 
Figure 1. TBARS evolution during the ripening process of both types of dry fermented sausages (mg malondialdehyde/kg product).

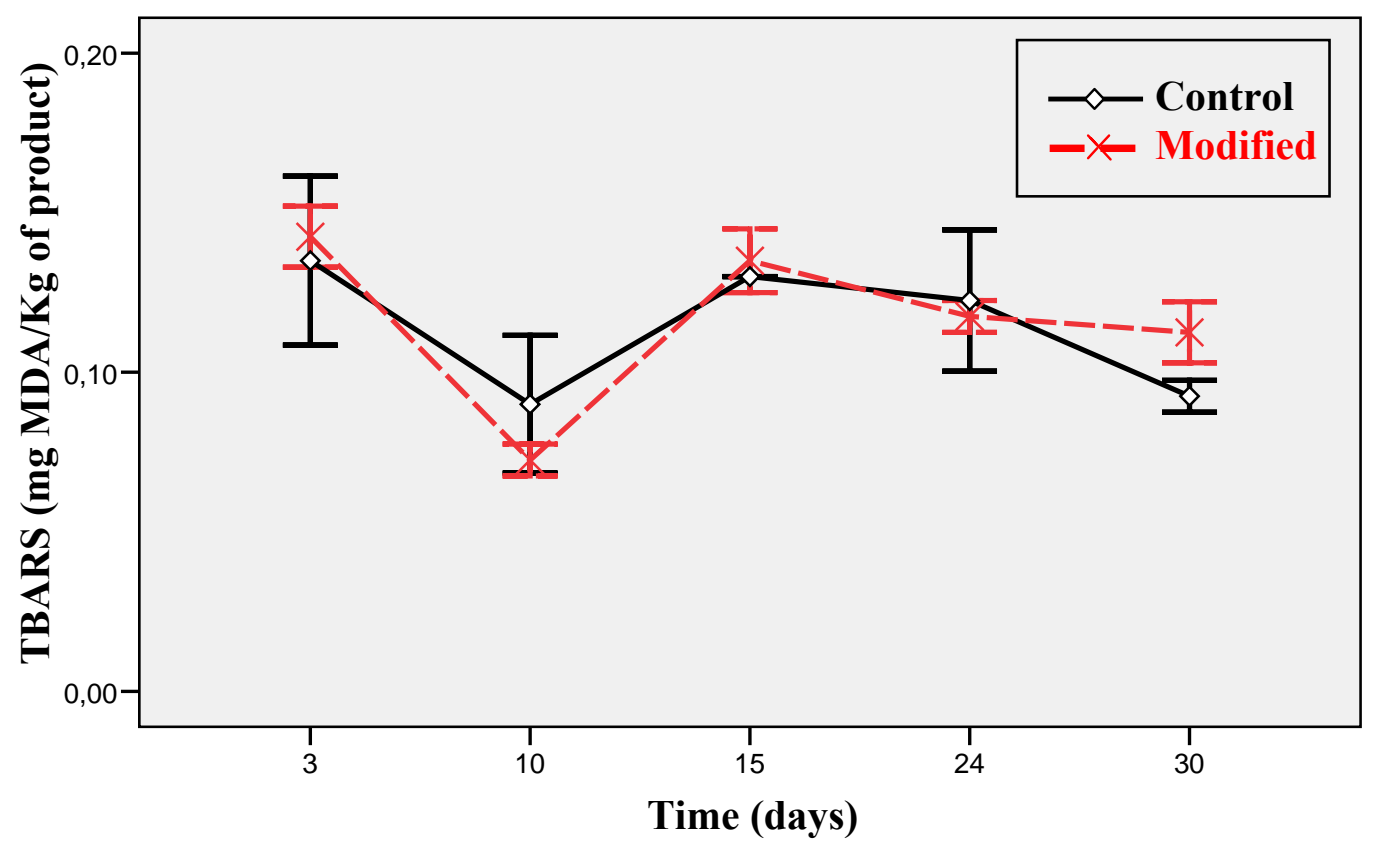


Table 1. Fatty acid composition of the mixture of linseed and algae oils, and of Control and Modified dry fermented sausages.

\begin{tabular}{|c|c|c|c|c|}
\hline & \multirow[b]{2}{*}{$\begin{array}{l}\text { Linseed/Algae oils } \\
\text { mixture }^{\mathrm{a}}\end{array}$} & \multicolumn{3}{|c|}{ Femented Sausages } \\
\hline & & Control $^{\mathrm{a}}$ & Modified $^{\mathrm{a}}$ & $\begin{array}{l}\mathbf{L S}^{\mathrm{b}} \\
\text { Student't } \\
\text { test }\end{array}$ \\
\hline Caprilic C8:0 & $0.30 \pm 0.00$ & $0.12 \pm 0.01$ & $0.14 \pm 0.00$ & $* * *$ \\
\hline Capric C10:0 & $0.91 \pm 0.01$ & $0.15 \pm 0.00$ & $0.20 \pm 0.00$ & $* * *$ \\
\hline Lauric C12:0 & $3.24 \pm 0.02$ & $0.09 \pm 0.00$ & $0.26 \pm 0.00$ & $* * *$ \\
\hline Myristic C14:0 & $7.69 \pm 0.09$ & $1.30 \pm 0.01$ & $1.64 \pm 0.01$ & $* * *$ \\
\hline Palmitic C16:0 & $6.79 \pm 0.01$ & $22.88 \pm 0.12$ & $21.38 \pm 0.02$ & $* * *$ \\
\hline t-Palmitoleic C16:1t & $0.04 \pm 0.00$ & $0.33 \pm 0.02$ & $0.26 \pm 0.00$ & $* * *$ \\
\hline Palmitoleic C16:1 & $2.10 \pm 0.05$ & $1.96 \pm 0.01$ & $1.98 \pm 0.01$ & $\mathrm{~ns}$ \\
\hline Stearic C18:0 & $1.75 \pm 0.05$ & $12.08 \pm 0.07$ & $11.34 \pm 0.01$ & $* * *$ \\
\hline Elaidic C18:1t & $0.06 \pm 0.01$ & $0.41 \pm 0.01$ & $0.34 \pm 0.03$ & $*$ \\
\hline Oleic C18:1 ( $\omega-9)$ & $23.01 \pm 1.19$ & $39.41 \pm 0.26$ & $38.05 \pm 0.07$ & $* * *$ \\
\hline Vaccenic C18:1 ( $\omega-7)$ & $0.38 \pm 0.01$ & $2.85 \pm 0.02$ & $2.76 \pm 1.00$ & $* * *$ \\
\hline$t$-Linoleic C18:2t & $0.03 \pm 0.00$ & $0.10 \pm 0.00$ & $0.10 \pm 0.00$ & ns \\
\hline$c$-t linoleic C18:1c.1t & $0.05 \pm 0.00$ & $0.05 \pm 0.00$ & $0.05 \pm 0.00$ & $* *$ \\
\hline$t-c$ linoleic C18:1t.1c & $0.07 \pm 0.00$ & $0.09 \pm 0.00$ & $0.09 \pm 0.00$ & ns \\
\hline 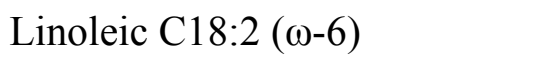 & $5.11 \pm 0.05$ & $15.21 \pm 0.09$ & $12.90 \pm 0.02$ & $* * *$ \\
\hline Arachidic C20:0 & nd & $0.05 \pm 0.00$ & $0.01 \pm 0.00$ & $* * *$ \\
\hline$\gamma$-linolenic C18:3 ( $\omega-6)$ & $0.06 \pm 0.00$ & $0.03 \pm 0.00$ & $0.03 \pm 0.00$ & ns \\
\hline Eicosenoic C20:1 ( $\omega-9)$ & $0.05 \pm 0.01$ & $0.77 \pm 0.00$ & $0.68 \pm 0.00$ & $* * *$ \\
\hline$\alpha$-linolenic C18:3 $(\omega-3)$ & $12.87 \pm 0.23$ & $0.92 \pm 0.01$ & $4.82 \pm 0.01$ & $* * *$ \\
\hline Eicosadienoic C20:2 ( $\omega-6)$ & nd & nd & nd & -- \\
\hline Behenic C22:0 & nd & $0.08 \pm 0.00$ & $0.07 \pm 0.00$ & $*$ \\
\hline Brasidic C20:1t & $0.08 \pm 0.01$ & $0.01 \pm 0.00$ & $0.01 \pm 0.00$ & $*$ \\
\hline Erucic C22:1 & nd & $0.14 \pm 0.00$ & $0.10 \pm 0.00$ & $* * *$ \\
\hline Eicosatrienoic C20:3 ( $\omega-3)$ & nd & nd & nd & -- \\
\hline Arachidonic C20:4 ( $\omega-6)$ & $0.03 \pm 0.00$ & $0.38 \pm 0.00$ & $0.39 \pm 0.03$ & ns \\
\hline Eicosapentaenoic C20:5 ( $\omega-6)$ & $0.10 \pm 0.03$ & $0.03 \pm 0.01$ & $0.05 \pm 0.01$ & $* *$ \\
\hline Nervonic C24:1 ( $\omega-9)$ & $0.03 \pm 0.00$ & $0.29 \pm 0.53$ & $0.12 \pm 0.00$ & ns \\
\hline Docosatrienoic C:22 ( $\omega-3)$ & nd & nd & nd & -- \\
\hline Docosapentaenoic C22:5 ( $\omega-6)$ & $0.09 \pm 0.00$ & $0.11 \pm 0.04$ & $0.11 \pm 0.00$ & $* * *$ \\
\hline Lignoceric C24:0 & $0.38 \pm 0.05$ & $0.10 \pm 0.00$ & $0.43 \pm 0.01$ & $* * *$ \\
\hline Docosapentaenoic C22:5 ( $\omega-3)$ & $0.14 \pm 0.00$ & nd & nd & -- \\
\hline Docosahexaenoic C22:6( $\omega-3)$ & $34.66 \pm 0.81$ & $0.05 \pm 0.00$ & $2.00 \pm 0.07$ & $* * *$ \\
\hline SFA & $20.68 \pm 0.09$ & $36.75 \pm 0.18$ & $35.05 \pm 0.04$ & $* * *$ \\
\hline MUFA & $25.56 \pm 1.16$ & $45.41 \pm 0.25$ & $43.68 \pm 0.07$ & $* * *$ \\
\hline PUFA & $53.06 \pm 1.06$ & $16.74 \pm 0.05$ & $20.29 \pm 0.07$ & $* * *$ \\
\hline$\omega-3$ & $47.77 \pm 1.02$ & $1.00 \pm 0.01$ & $6.86 \pm 0.07$ & $* * *$ \\
\hline$\omega-6$ & $5.28 \pm 0.05$ & $15.74 \pm 0.05$ & $13.43 \pm 0.03$ & $* * *$ \\
\hline$\omega-6 / \omega 3$ & $0.11 \pm 0.00$ & $15.69 \pm 0.15$ & $1.96 \pm 0.02$ & $* * *$ \\
\hline PUFA/SFA & $2.57 \pm 0.04$ & $0.46 \pm 0.00$ & $0.58 \pm 0.00$ & $* * *$ \\
\hline
\end{tabular}




\begin{tabular}{lllll} 
PUFA+MUFA/SFA & $3.80 \pm 0.02$ & $1.69 \pm 0.01$ & $1.83 \pm 0.00$ & $* * *$ \\
trans & $0.32 \pm 0.01$ & $0.99 \pm 0.02$ & $0.85 \pm 0.04$ & $* * *$ \\
\hline
\end{tabular}

${ }^{\mathrm{a}} \mathrm{Fatty}$ acids are expressed in $\mathrm{g} / 100 \mathrm{~g}$ of fat as mean \pm standard deviation. ${ }^{\mathrm{b}}$ Student't test compare differences between both types of dry fermented sausages. LS (level of significance):.ns (not significant); $p$ $>0.05 ; * \mathrm{p}<0.05 ; * * \mathrm{p}<0.01 ; * * * ; \mathrm{p}<0.001$. 
Table 2. Instrumental colour CIEL*a*b* evaluation of Control and Modified dry fermented sausages.

\begin{tabular}{lccc}
\hline & Control $^{\mathrm{a}}$ & Modified $^{\mathrm{a}}$ & LS $^{\mathrm{b}}$ \\
\hline $\mathbf{L}^{*}$ & $44.72 \pm 0.99$ & $45.10 \pm 1.48$ & $\mathrm{~ns}$ \\
$\mathbf{a}^{*}$ & $22.09 \pm 2.26$ & $19.55 \pm 1.32$ & $* * *$ \\
$\mathbf{b}^{*}$ & $17.33 \pm 1.99$ & $13.68 \pm 1.12$ & $* * *$ \\
Chroma & $28.08 \pm 2.91$ & $23.86 \pm 1.72$ & $* * *$ \\
Hue & $38.08 \pm 1.57$ & $34.95 \pm 0.50$ & $* * *$ \\
\hline
\end{tabular}

${ }^{\mathrm{a}}$ Results are expressed as mean \pm standard deviation. ${ }^{\mathrm{b}} \mathrm{LS}$ (level of significance): ns (not significant); $\mathrm{p}>0.05 ; * \mathrm{p}<0.05 ; * \mathrm{p}<0.01$; $* * * ; \mathrm{p}<0.001$. 
Table 3. Sensory scores of triangular test for Control vs Modified dry fermented sausages.

\begin{tabular}{lcccc}
\hline \multicolumn{5}{c}{ Control vs Modified } \\
\hline & $\begin{array}{l}\text { Appearance } \boldsymbol{n} \\
(\% \text { within group) }\end{array}$ & $\begin{array}{l}\text { Odor } \boldsymbol{n} \\
(\% \text { within group) }\end{array}$ & $\begin{array}{l}\text { Taste } \boldsymbol{n} \\
(\% \text { within group) }\end{array}$ & $\begin{array}{l}\text { Juiciness } \boldsymbol{n} \\
(\% \text { within group) }\end{array}$ \\
\hline $\begin{array}{l}\text { Correct replies } \\
\text { Incorrect }\end{array}$ & $6(37.5 \%) \mathrm{ns}$ & $7(43.75 \%) \mathrm{ns}$ & $6(37.5 \%) \mathrm{ns}$ & $6(37.5 \%) \mathrm{ns}$ \\
replies & $10(62.5 \%)$ & $9(56.25 \%)$ & $10(62.5 \%)$ & $10(62.5 \%)$ \\
$\begin{array}{l}\text { Total } \\
\text { For } \mathrm{n}=16, \text { the difference between samples was significant if the number of correct answers was } 9 \\
(\mathrm{p}<0.05), 11(\mathrm{p}<0.01) \text { and } 12(\mathrm{p}<0.001) .\end{array}$ \\
\end{tabular}

